\title{
Save the Date!
}
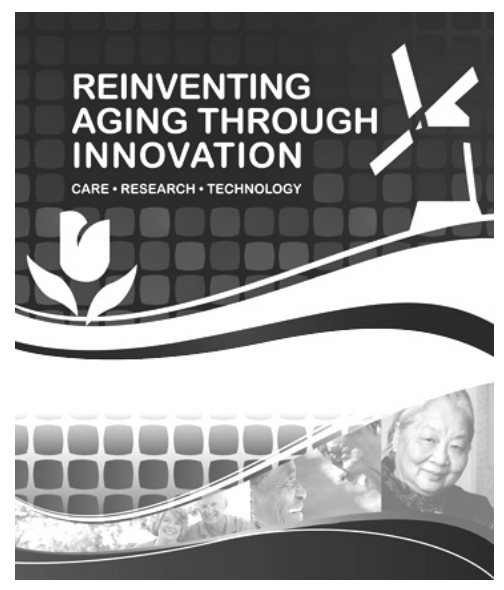

\section{$15^{\text {th }}$ International Congress Reinventing Aging Through Innovation Care • Research • Technology}

\author{
6-9 September 2011 \\ The Hague, The Netherlands
}

The International Psychogeriatric Association (IPA) is committed to bringing the newest information from the field to its scientific programs.

For information contact the IPA Secretariat:

Email: ipa@ipa-online.org Web: www.ipa-online.org

IPA ... Better Mental Health for Older People

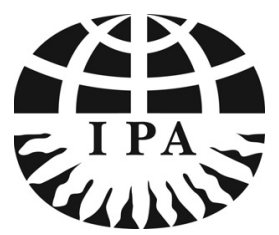


Complete Guide to

Behavioral and

Psychological

Symptoms of

Dementia

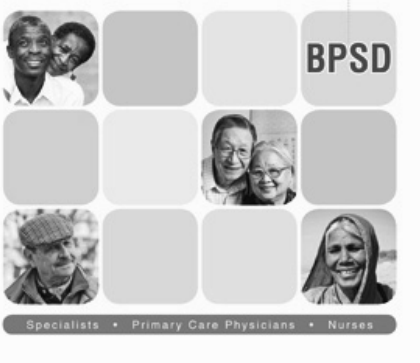

\section{Newly Revised!}

\section{The IPA Complete Guide to Behavioral and Psychological Symptoms of Dementia (BPSD)}

BPSD are recognizable, understandable and treatable. Appropriate management strategies of BPSD are important factors in improving our care of dementia patients and their caregivers.

Developed in 1998, updated in 2002 and recently revised, the International Psychogeriatric Association (IPA) offers this popular comprehensive resource with modules that provide a useful overview of the presentation and causes of BPSD, giving constructive guidance on treatment interventions, both pharmacological and non-pharmacological, coupled with information on caregiver education and support.

Modules:

1 - An introduction to BPSD

5 - Non-pharmacological treatments

2 - Clinical issues

6 - Pharmacological treatments

3 - Etiology

4 - Role of family caregivers

7 - Cross-cultural and transnational considerations

... PLUS guides specifically designed for nurses and primary care physicians are also available!

Available online at no charge to IPA members! Join IPA today!

www.ipa-online.org 


\section{Coming soon as a webinar!}

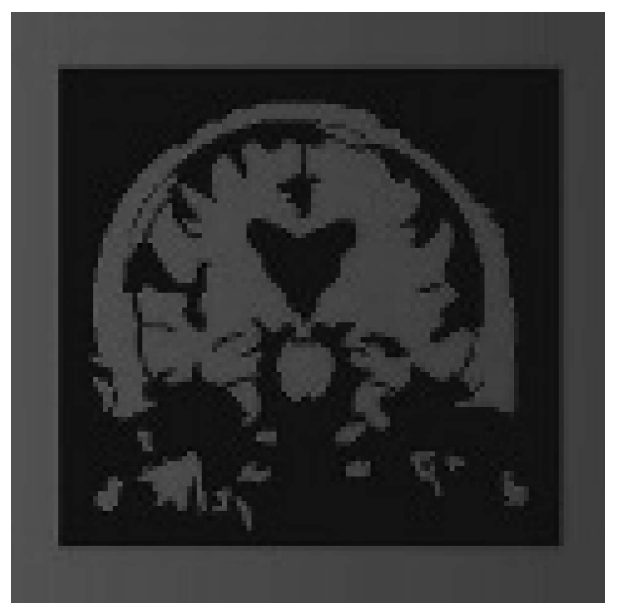

\section{IPA Neuroimaging in Dementia}

\section{Attend this popular IPA workshop and never leave your office!}

Starting soon, IPA is planning to offer this program online. Presented by the same outstanding international experts, providing information on the latest advances in neuroimaging with real life examples and using an interactive teaching style, the webinars are destined to be as successful as the original workshop which has been offered many times and always receiving excellent evaluations!

\section{For more information,} watch the IPA Bulletin and IPA Website.

Email: ipa@ipa-online.org Web: www.ipa-online.org IPA ... Better Mental Health for Older People

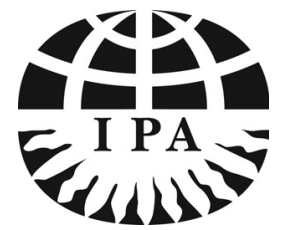




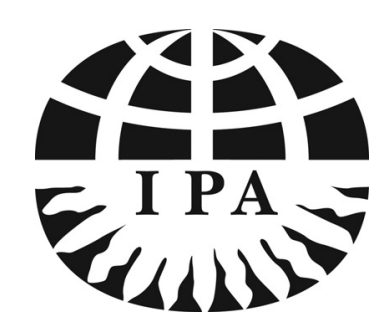

International Psychogeriatric Association (IPA)

Representing more than 66 countries around the world, IPA is a unique and diverse professional healthcare community promoting better geriatric mental health - across disciplines, across borders, and across geriatric issues. Psychiatrists, Scientists, Neurologists, Geriatricians, Primary Care Physicians, Epidemiologists, Nurses, Psychologists, Occupational Therapists, Social Workers, and many other healthcare professionals come to the IPA community from all over the globe to discuss, learn, share, and research information about behavioral and biological aspects of geriatric mental health. IPA's leaders and members contribute their wealth of expertise and knowledge from the research, clinical, education, service and program development arenas.

There are many benefits to being a member of IPA, including a subscription to this peer-reviewed journal, International Psychogeriatrics. For more information please contact info@ipa-online.org.

\title{
IPA Board of Directors
}

\author{
Officers \\ Masatoshi Takeda, President, Japan \\ Jacobo Mintzer, President-Elect, United States \\ Jill Rasmussen, Treasurer, United Kingdom \\ Horácio Firmino, Treasurer-Elect, Portugal \\ Daniel O'Connor, Secretary, Australia \\ Helen Fung-kum Chiu, Immediate Past President, Hong Kong SAR PR China
}

$\begin{array}{cc}\text { Heii Arai, Japan } & \text { Directors } \\ \text { Sabine Bährer-Kohler, Switzerland } & \text { Jay Luxenberg, United States } \\ \text { Olusegun Baiyewu, Nigeria } & \text { Kiyoshi Maeda, Japan } \\ \text { Susan Benbow, United Kingdom } & \text { Raimundo Mateos, Spain } \\ \text { Cássio Machado de Campos Bottino, Brazil } & \text { John T. O'Brien, United Kingdom } \\ \text { Ramón Cacabelos, Spain } & \text { Nancy Pachana, Australia } \\ \text { David Conn, Canada } & \text { Leonardo Pantoni, Italy } \\ \text { Peter Paul De Deyn, Belgium } & \text { Anne Margriet Pot, Netherlands } \\ \text { Brian Draper, Australia } & \text { Mary Sano, United States } \\ \text { Serge Gauthier, Canada } & \text { Guk-Hee Suh, South Korea } \\ \text { Doh Kwan Kim, South Korea } & \text { Gregory Swanwick, Ireland } \\ \text { Ken Laidlaw, United Kingdom } & \text { Frans R.J. Verhey, Netherlands } \\ \text { Carlos de Mendonça Lima, Brazil } & \text { Huali Wang, PR China }\end{array}$

Executive Director

Susan M. Oster, United States 


\section{Encourage a Colleague to Join}

The International Psychogeriatric Association (IPA) is the leading multidisciplinary, international organization dedicated to the advancement of geriatric mental health knowledge.

\section{Benefits of IPA Membership Include}

- An opportunity to interact with colleagues around the world who share an interest in advancing research, education, and theory about mental health in older people

- Education and meetings reflecting the many disciplines in Psychogeriatrics and the collective expertise of the world; IPA members receive special "members only" rates for all our meetings and activities

- A subscription to International Psychogeriatrics, IPA's peer-reviewed journal, which includes eight issues per year and any additional special-focus supplements

- The IPA Bulletin, an informative quarterly newsletter

- IPA Online - the IPA website - including member area with special features including access to fellow members, and the IPA Learning Portal

- Support the growth of Psychogeriatrics around the world, including contributing to the Sponsored Member Program to help associations in developing countries pass knowledge to their members

- Behavioral and Psychological Symptoms of Dementia (BPSD) Education Materials are available to IPA members in electronic format at no charge. The BPSD materials include the newly revised seven module IPA Complete Guide to $B P S D$, the Primary Care Physician's Guide to BPSD, and the Nurses' Guide to BPSD.

IPA's membership dues have been adjusted to accommodate the needs of a wide variety of colleagues worldwide. To find out what the membership rates are for your country, please visit www.ipa-online.org.

To join or to obtain a membership application, bookmark the IPA website at http://www.ipa-online.org, or contact:

International Psychogeriatric Association

E-mail: membership@ipa-online.org Website: http://www.ipa-online.org

Telephone: +1.847.501.3310 • Fax: +1.847.501.3317

550 Frontage Road, Suite 3759

Northfield, IL 60093 USA

\section{IPA ... Better Mental Health for Older People}




\section{CAMBRIDGE}

\section{Medicine}

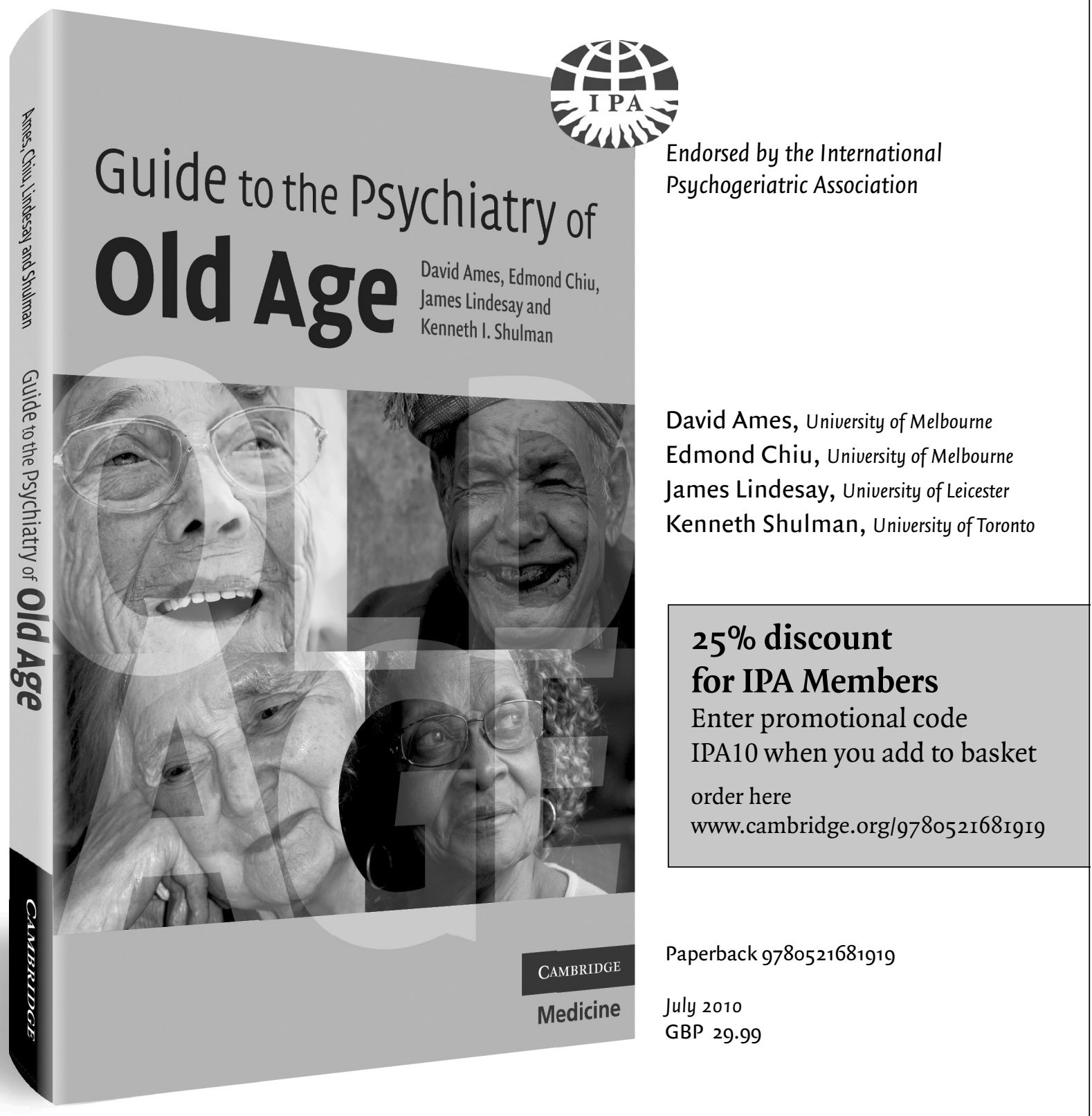

\section{Compact, accessible and affordable}

Each chapter is sharp, clear and practical, enhanced by tables and diagrams for quick assimilation and reference on the ward or in the clinic Coverage also includes legal and ethical issues, and the neglected topic of alcohol and drug abuse in the elderly 


\section{International
Psychogentios}

\section{Scope and contributions}

International Psychogeriatrics is written by and for those doing clinical, teaching, and research work with older people. It is the official journal of the International Psychogeriatric Association (IPA) and is published by Cambridge University Press, Cambridge, UK. Although it is primarily concerned with psychogeriatrics, the journal welcomes contributions from all concerned with the field of mental health and aging. Original research papers are particularly sought.

Contributions include original research articles, case reports, reviews of the literature, book reviews, letters to the editor, and editorials. Apart from editorials and book reviews, which are commissioned, contributions to International Psychogeriatrics are spontaneously written and submitted by authors. Papers are reviewed by two expert reviewers selected by the Editor-in-Chief. At present, about half of the papers submitted are accepted for publication. The journal's Science Citation Index impact factor is 2.506 (2009). Submission of a paper implies that it is neither under consideration for publication elsewhere, nor previously published in English. Manuscripts must be formatted double-spaced with ample margins on all sides and the pages should be numbered. International Psychogeriatrics uses the spelling of American English. Manuscripts written by those whose primary language is not English should be edited carefully for language prior to submission. The journal has a Language Assistance Panel consisting of both native English speakers willing to check mauscripts for style prior to submission, and bilingual experts willing to assist with the translation of manuscripts into English. Further details including contact information for individual panel members can be found at both the journal and IPA websites (journals.cambridge.org/ipg and www.ipa-online.org).

An up to date version of the journal's instructions for contributors can be found at the International Psychogeriatrics website journals. cambridge.org/ipg. Please read these instructions carefully before submitting articles. Articles that are not prepared in accordance with these guidelines will be returned to authors.

Manuscripts should be submitted online via our manuscript submission and tracking site, <http://mc.manuscriptcentral.com/ipg>. Full instructions for electronic submission are available directly from this site.

Important Addresses

Office of the Editor-in-Chief

Professor David Ames, Editor-in-Chief, International Psychogeriatrics

Normanby House,

St George's Hospital,

283 Cotham Rd.,

Kew, Victoria 3101,

Australia

Email:ipaj-ed@unimelb.edu.au

$\mathrm{Tel}+61398160485$

Fax +61398160477

\section{For business matters:}

Ms. Susan M. Oster

Managing Editor, International Psychogeriatrics

International Psychogeriatric Association

550 Frontage Road,

Suite 3759

Northfield, IL 60093

USA

Email:ipa@ipa-online.org

Tel: +1 8475013310

Fax: +1 8475013317

Web: www.ipa-online.org

\section{For book review matters:}

Dr. Michael Philpot

Maudsley Hospital,

Mental Health of Older Adults Directorate

115 Denmark Hill,

London SE5 8AZ

U.K.

Email

mike.philpot@slam.nhs.uk

Tel: +44(0)203228 1640

Fax: +44 (0)203228 1619 .

This journal issue has been printed on FSC-certified paper and cover board. FSC is an independent, non-governmental, not-for-profit organization established to promote the responsible management of the world's forests. Please see www.fsc.org for information.

Enquiries about advertising should be sent to the Journal's Promotion Department of the Cambridge or American Branch of Cambridge University Press. 


\section{International Psychogeriatrics}

\section{cowrerse}

Guest Editorial 1023 Optimizing mental health in long-term care homes

Special Issue 1025 Prevalence of psychiatric disorders among older adults in long-term care homes: a systematic review

Articles Dallas Seitz (Canada), Nitin Purandare (U.K.) and David Conn (Canada)

1040 Course of neuropsychiatric symptoms in residents with dementia in long-term care institutions: a systematic review Roland Wetzels, Sytse Zuidema, lepke Jansen, Frans Verhey and Raymond Koopmans (Netherlands)

1054 Comprehensive assessment of depression and behavioral problems in long-term care Raymond T. C. M. Koopmans, Sytse U. Zuidema, Roeslan Leontjevas and Debby L. Gerritsen (Netherlands)

1063 Mental health service delivery in long-term care homes John Snowdoni (Australia)

1072 Principles of good care for long-term care facilities Maggie C. Gibson (Canada), Mary W. Carter (U.S.A.), Edward Helmes (Australia) and Anna-Karin Edberg (Sweden)

1084 Long-term care for people with dementia: environmental design guidelines Richard Fleming (Australia) and Nitin Purandare (U.K.)

1097 Recommendations for staff education and training for older people with mental illness in long-term aged care Wendy Moyle (Australia), Mei Chi Hsu (Taiwan), Susan Lieff (Canada) and Myrra Vernooij-Dassen (Netherlands)

1107 Screening for mental disorders in residential aged care facilities Nancy A. Pachana, Edward Helmes, Gerard J. A. Byrne (Australia), Barry A. Edelstein (U.S.A.), Candace A. Konnert (Canada) and Anne Margriet Pot (Netherlands)

1121 Psychosocial interventions for dementia patients in long-term care Myrra Vernooij-Dassen, Emmelyne Vasse, Sytse Zuidema (Netherlands), Jiska Cohen-Mansfield (U.S.A.) and Wendy Moyle (Australia)

Review Articles 1129 Ethical and practical concerns of surveillance technologies in residential care for people with dementia or intellectual disabilities: an overview of the literature Alistair R. Niemeijer, Brenda J. M. Frederiks (Netherlands), Ingrid I. Riphagen (Norway), Johan Legemaate, Jan A. Eefsting and Cees M. P. M. Hertogh (Netherlands)

1143 Depression in nursing homes John Snowdon (Australia)

Original Research 1149 Changes to psychotropic medications in the six months after admission to nursing homes in Melbourne, Australia Articles Daniel W. O'Connor, Joanne Griffith and Kate McSweeney (Australia)

1154 One-week prevalence of depressive symptoms and psychotropic drug treatments among old people with different levels of cognitive impairment living in institutional care: changes between 1982 and 2000 Hugo Lövheim, Ellinor Bergdahl, Per-Olof Sandman, Stig Karlsson and Yngve Gustafson (Sweden)

1161 Depression in the first year of stay for elderly long-term nursing home residents in the U.S.A. D. R. Hoover, M. Siegel, J. Lucas, E. Kalay, D. Gaboda, D. P. Devanand and S. Crystal (U.S.A.)

1172 The meanings of screams in older people living with dementia in a nursing home Anne Bourbonnais and Francine Ducharme (Canada)

1185 Social support and psychological well-being of nursing home residents in Hong Kong

Letter 1191 Sheung-Tak Cheng, Coty Kit Ling Lee and Pizza Ka-Yee Chow (Hong Kong) 